\title{
Prediction model of fatigue life of Ni-based single crystal superalloy specimen with single hole based on the EIFS
}

\author{
xiangzhen $x u e^{1}$, wenxian $\mathrm{li}^{1}$, and Zhixun $\mathrm{Wen}^{2}$ \\ ${ }^{1}$ Affiliation not available \\ ${ }^{2}$ Northwestern Polytechnical University
}

July 22, 2020

\begin{abstract}
A method of predicting the fatigue life under multi-axial loads based on the Paris law and EIFS was proposed. The crack shape factor of Ni-based single crystal superalloy material with single hole was calculated. Meanwhile, the Miss stress, Max principal strain and Magnitude displacement of the specimen along the dangerous path under different load stresses, initial crack and stress ratio were investigated by Abacus. The fatigue life situation of Ni-based single crystal superalloy material with single hole has different working conditions, which were predicted and validated by test eventually. The results show that the crack propagates at a faster speed under large load stresses, leading to a lower fatigue life. The larger initial crack length results in faster the crack growth on the specimen, and the shorter its fatigue life is. For the different stress ratios, smaller stress ratio can lead to lower fatigue life. Meanwhile, the fatigue life of Ni-based single crystal superalloy material with single hole predicted by the presented method herein based on the Paris law and EIFS agrees well with the fatigue test results.
\end{abstract}

\section{Hosted file}

Prediction model of fatigue life of Ni-based single crystal superalloy specimen with single hole based available at https://authorea.com/users/345222/articles/471512-prediction-model-of-fatiguelife-of-ni-based-single-crystal-superalloy-specimen-with-single-hole-based-on-the-eifs 